\title{
Editorial
}

By Richard J. Wollensak, SPIE Awards Committee Chairman, 1979

\section{The Rudolf Kingslake Medal and Prize}

Optical Engineering has grown with our Society over the years, and today enjoys an international reputation as a journal of archival quality. The articles and papers which have been published within its covers are referenced more and more frequently in new works, attesting to the stature of Optical Engineering within the community. I am sure most readers are aware of its reference value in the daily practice of our optical engineering profession.

I am not sure, however, that many of the readers of Optical Engineering realize that a major SPIE award is presented annually to recognize the most noteworthy paper which has been published in this journal each calendar year. The award is the Rudolf Kingslake Medal and Prize, and was established in 1974. It has been named in honor of Rudolf Kingslake, Professor of Geometrical Optics at the University of Rochester, a scientist who has performed extensive research in lens design, optical instrument development, and lens testing. He was director of optical design at Eastman Kodak Company for thirty years, until his retirement in 1969. Professor Kingslake has often been called the father of modern lens design, and is still very active in that field today.

Each year, under the guidance of the Awards Committee Chairman, the Society empanels a jury of five or six recognized experts to review all of the technical papers and articles which have been published during the preceding year in Optical Engineering. The paper judged to be the most original and noteworthy by this distinguished panel is awarded the Rudolf Kingslake Medal and Prize. The author of the winning paper receives a silver medal and an honorarium of $\$ 1000$ in recognition of his work.

Since the inception of this award, the Society has so honored five winning papers. I believe that there has been a common thread in all five, and that is innovative engineering, showing both originality and quality. The winning papers have spanned a variety of subjects in our field, but each has shared new insights which will be of great value to other practitioners.

For the reader's reference, I submit the listing of the five Kingslake Award winners to date:

- "Skylab Multispectral Scanner (S-192)_Optical Design and Operational Imagery," by Irving R. Abel and B. R. Reynolds, Honeywell Radiation Center, Optical Engineering July/August 1974 (13:4:292).

- "A High Sensitivity Moire Grid Technique for Studying Deformation in Large Objects," by J. M. Burch and C. Forno, National Physical Laboratory (England), Optical Engineering March/April 1975 (14:2:178).

- "Microdensitometer Optical Performance: Scalar Theory and Experiment," by Richard E. Swing, National Bureau of Standards, Optical Engineering November/December 1976 (15:6:559).

- "Optical Processing in Radionuclide Tomographic Image Reconstruction," by David B. Kay and Brian J. Thompson, Institute of Optics, University of Rochester, Optical Engineering January/February 1977 $(16: 1: 45)$.

- "Computationally Directed Axisymmetric Aspheric Figuring," by Norman J. Brown, Lawrence Livermore Laboratory, Optical Engineering November/December 1978 (17:6:602).

In the September/October 1979 issue of Optical Engineering, John Caulfield published a straightforward editorial arguing for more optical engineers to publish their work. He cited specific reasons for considering publication. I would heartily endorse his arguments and add an additional reason of my own: every published paper is reviewed for the Kingslake Medal and Prize. The prestige and honor accompanying the winning paper is significant, as is the honorarium. I urge each of you to consider this potential additional benefit when you are deciding whether you should submit a paper for publication in Optical Engineering. 


\section{Who Created the Information Management System?}

\author{
Leo Beiser \\ Leo Beiser Inc., 151-77 28th Avenue, Flushing, New York 11354
}

A unique satisfaction is derived from philosophical fantasy. Perhaps the reader will share in this joy of structuring a totally fictitious situation from fragments of experience. This work, originally prepared as a Keynote Address for the Laser Recording and Information Handling seminar at the San Diego SPIE symposium of August 27-30, 1979 (SPIE Proceedings Volume 200) is dedicated to the many people who can identify with the situations which validate and perpetuate our legendary models.

\section{Abstract \\ A satire on team effort.}

\section{The Prologue}

If the Keynoter is to extract wisdom from a treasury of observations-to reveal judgments which integrate "mature experience"-let me assure you that this address is being approached very cautiously. My definition of experience is an accumulation of "unmistakes." Mature experience means that one has had the time to organize the mistakes so that he stumbles over them less frequently.

With this disclaimer, we can now introduce the controversial subject of determining who, in fact, created "The System." Any system will do, so long as it resulted from team effort. Since we all do "information management," that's the system. Since our team expended all the effort, that's the subject. But, who really did it? Who created the information management system?

I trust you will soon conclude that we are to witness a drama of individuals-people and organizations-each making its own judgments. When success is self-evident, such as at the "victory celebration," then in retrospect, the creating "clearly" resulted from the unifying and balanced leadership of skillful Project or Group or Team or Person management. At other times-and, in fact, at the same time-"mature experience" reveals that the experience unfolds more like this:

\section{The Program}

Let us create an Information Management System. What is an Information Management System? Not to be confused with the common computer-based phrase, "Management Information System" (MIS), an Information Management System is one which manages information. Not just for management; it could be for anybody, or for any agency. Since information often includes graphics, to be modified, added to, deleted and/or transmitted, it usually acquires an image-forming configuration which allows for the scanning or digitizing of a document and the (re)creation of it, or a portion of it, along with provision for additional entries and modifications. With this background of hypothetical but quite realistic need, our heroic organization now sets out to develop this new system.

The specifications appear, as usual, in cold tabular form. Thus, the first task announced by the Project Director is the meeting of its team of group managers to formulate a plan for subsequent development. Each team member is charged with the responsibility for reviewing the specs and configuring a total INFORMATION MANAGEMENT SYSTEM BLOCK DIAGRAM. Although the specifications call for a laser-based system, it might have required a CRT, an LED or a direct electron beam scanning source. The significance of our saga-soon to become apparent-has no bearing on which is used. Our focus is on people. The Cast of Characters is:

\begin{tabular}{|c|c|c|}
\hline Name & Responsibility & Listing \\
\hline Ironside M. King & Project Director & .I. M. King \\
\hline Claude deCharts & Administrator. . & C. deCharts \\
\hline Brenda U. Merry & Secretary & B. U. Merry \\
\hline Karl O. Heerent. & Laser Systems. & K. O. Heerent \\
\hline Vern R. Y. Stably & Control Systems & V.R.Y.Stably \\
\hline Ira C. Light & Optical Systems & .1. C. Light \\
\hline Victor R. Stuffers & Packaging Department & V. R. Stuffers \\
\hline Xavior Sellers... & Marketing Manager. & .X. Sellers \\
\hline Guy Wiz & Projectionist's Assistan & G. Wiz \\
\hline
\end{tabular}

These are representative characters. More exist. But, no more are required to develop our story.

\section{The Development}

I. M. King, the Project Director (via his Administrator, C. deCharts and Secretary, B. U. Merry) convened a meeting at the prescribed date to review the system block diagrams and configure an approach.

King heralded this new system requirement as an opportunity to demonstrate what they can do together, requiring that his groups operate in supreme synchronism toward creating a unified and totally effective system. To demonstrate their unanimity, King had asked each group manager to present his interpretation of the entire system block diagram. The first speaker was Manager of the Laser Department, K.O.Heerent.

K. O., as Heerent was called, radiated as he projected the INFORMATION MANAGEMENT SYSTEM BLOCK DIAGRAM [Figure 1] on the Conference Room screen-for all to rejoice at the prospect of incorporating the Laser Department's new laser into this new and important program. K. O. illustrated the refinement of his new laser, complete with advanced precision alignment screws (which in the past have demonstrated their importance by requiring frequent adjustment) and indicated how the laser merged with the rest of the system, identifying all its major minuscule modules.

The Projectionist's Assistant, Guy Wiz (or Wiz, Guy) or simply, G. Wiz-destined for heroism in our story-excused himself for the interruption and asked, "What is the wavelength and power output?" K. O. Heerent responded without hesitation, "As required by the System, clearly represented in the comprehensive block diagram."

\section{All rejoiced.}

King then called upon his Manager of Control Engineering, V. R. Y. Stably, to present his block diagram of the INFORMATION MANAGEMENT SYSTEM [Figure 2]. According to Stably, a balanced representation of the System was projected on the Conference Room screen. He then explained that the critical system specifications could be met only with his new multifunctional regulating controls, as represented here-to compensate for the notably noisy and unstable K.O. Lasers.

Responding to G. Wiz's admittedly naive question about the need for additional high gain position and velocity control systems, retorted Stably, "Obviously to override the loose bearings and nonlinear drive assemblies typically designed in to our equipment."

\section{All relaxed.}

The next presentation of the INFORMATION MANAGEMENT SYSTEM BLOCK DIAGRAM [Figure 3] was by I. C. Light, Head of Optical Engineering. Everyone saw the Light projection as a masterpiece of synergistic representation, with more arrowheads pointing to and from things off the diagram than ever attempted by anyone else. Then Light beamed with pride, stating only in an optical block diagram may one introduce folding mirrors, not only to reflect packaging, but to fit the lines on the page.

Whereupon, G. Wiz observed, respectfully, that while he was running photocopies of V. R. 


\section{Honeywell announces:}

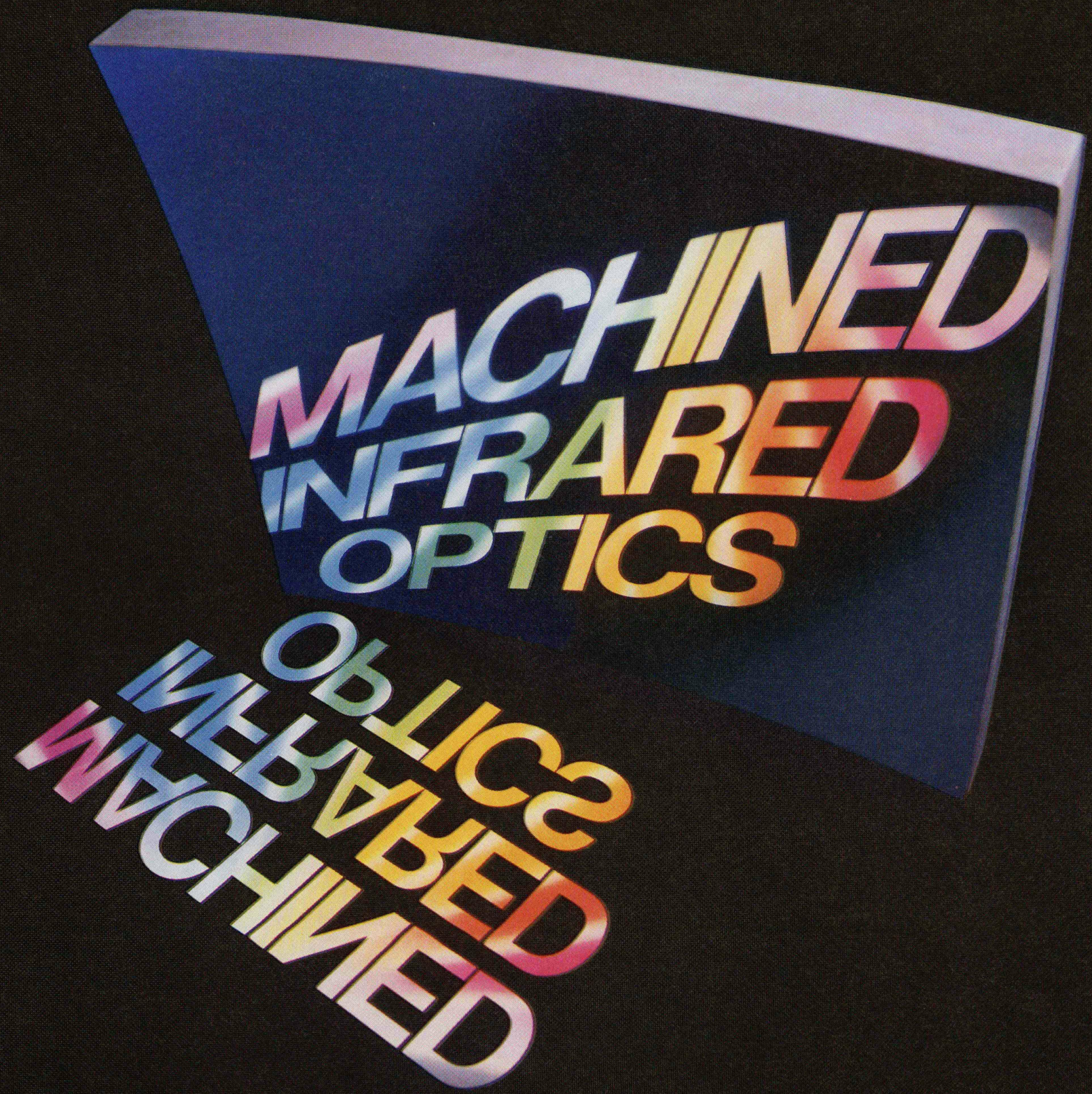

\section{FasterThan Conventional Methods}

Honeywell has successfully applied the emerging technology of diamond turning to reduce the finishing of infrared optics by $1 / 4$ to $3 / 4$ the time of conventional lapping and polishing.

\section{Tested ToYour Specifications}

In addition to single and two-axis

(CNC/laser feedback) lathes for ultra-precise shapes and mirror finishes, our capability includes a computer-generated hologram aspheric interferometer and infrared LUPI, OTF, and scatter testers.

\section{Proven Results In Any Quantity}

We've fine-tuned this production capability in fulfilling several in-house contracts. The exceptional payback has led us to expand our operation to serve the needs of the E-O community.

\section{The Bottom Line: Lower Cost}

Let us help you reduce the high cost of infrared lenses and mirrors.

Write or call: Floyd Johnson, Honeywell Electro-Optics Center, 2 Forbes Road, Lexington, MA 02173. (617) 862-6222 Ext. 600.

Opportunities exist for engineers and scientists. 
Stuffers's Packaging Department Block Diagram (G. Wiz is an Assistant Copy Operator when he is not assisting making projections), he could not help but notice that V. R. stuffed more folding mirrors into the package than were represented in Light's diagram. Apparently prepared for this illuminating Wiz remark, Light reflected that the two designs were balanced completely by Stuffers omitting some of his pellicle beam splitters-the relative transmission calculation of which reveals a ratio of light throughput between Light's and Stuffers's as

$$
\text { Light: } \text { Stuffers }=1.07683: 1
$$

Bright Light was quite right. All awaited Stuffers.

The definite INFORMATION MANAGEMENT SYSTEM BLOCK DIAGRAM [Fig. 4] by Packaging Engineering's V.R. Stuffers was precisely configured in modular form, replete with connectors, links, castings and brackets-every subassembly in its place, with no place to spare.

King pondered over this achievement of packaging finality -especially remarkable considering that usually no one fills-in Stuffers, and he confers with no one as to what is to fill the packages. Based, however, upon the preceding presentation by Light, Head of Optics, at least they talked about mirrors.

With an inevitable G. Wiz interjection of self-consciously mundane significance, it was learned, to King's chagrin, that the environmental requirements from the customer are yet to arrive in a forthcoming specification! (G. Wiz is an Assistant Mail Clerk when he is not assisting projections or copy.) "Perhaps," said C. deCharts, apparently to buffer Stuffers, "when we tabulate those fine design characteristics, the Customer will make the environment fit the package."

That left old King cold. And, said Merry, "Unsold was he."

"That," declared King, "is a job for our Marketing Manager, X. Sellers." "Let's see," said he, "how he sells it."

All who could see, saw.

Between the firm packaging just expressed by Stuffers and X. Sellers's INFORMATION MANAGEMENT SYSTEM BLOCK DIAGRAM [Fig. 5] now in view, the modules appear ready for pricing, promotion, \& production. Sellers intentionally highlighted nomenclature on only the supremely important items: "The Laser," "Page in here," and "Copy out here," all deftly exhibited by attractive female office personnel.

As an aside, G. Wiz wondered aloud why the outside of the unit looked so much like that by Stuffers, since King proclaimed that Stuffers usually consorted with no one. Sellers immediately admitted that he used his browsing prerogative to sneak an advance look at Stuffers's stuffings. While he was equally ignorant of what was to go in, Sellers made sure the outside looked like something important was, in fact, inside.

All were sold, thought Sellers.

\section{The Awakening}

King proclaimed a royal pain, and that it was time to muster forces. Acknowledging the outstanding superficial presentations by each of his group leaders, several things, he said, just didn't quite unite. In particular-

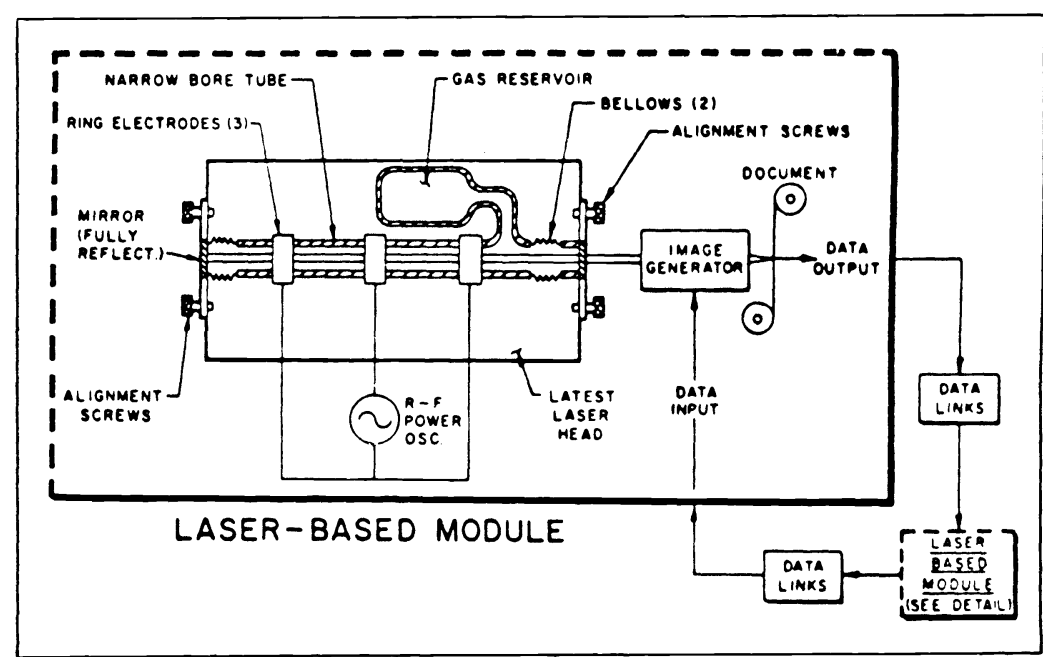

Fig. 1. Information Management System Block Diagram, by K. O. Keerent, Mgr. Laser Systems.

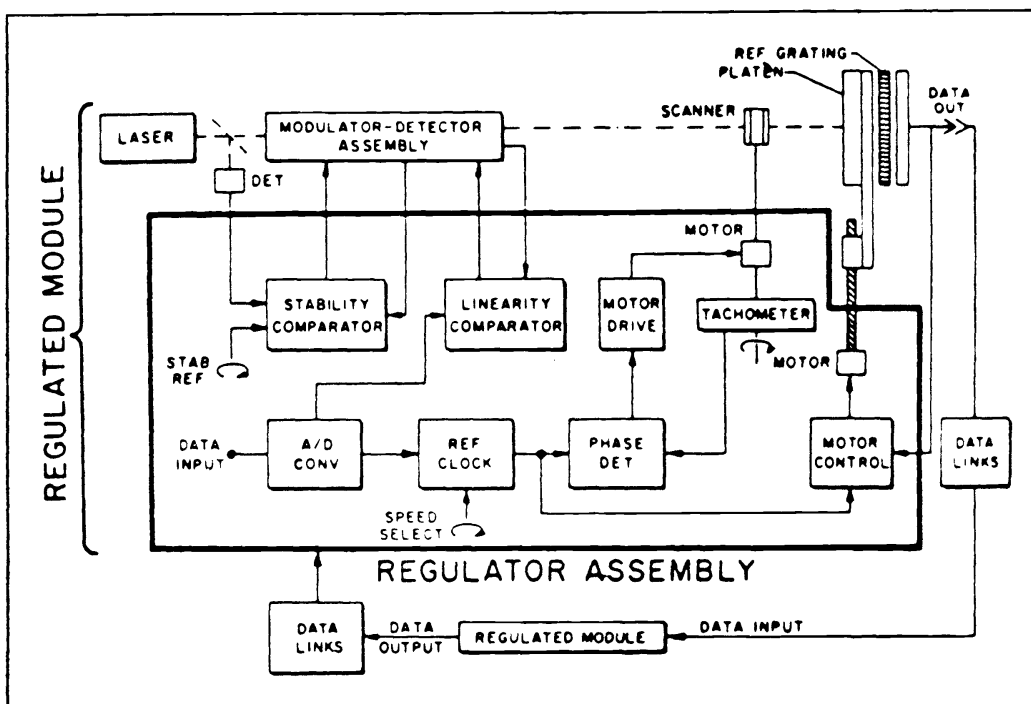

Fig. 2. Information Management System Block Diagram, by V. R. Y. Stably, Mgr. Control Systems.

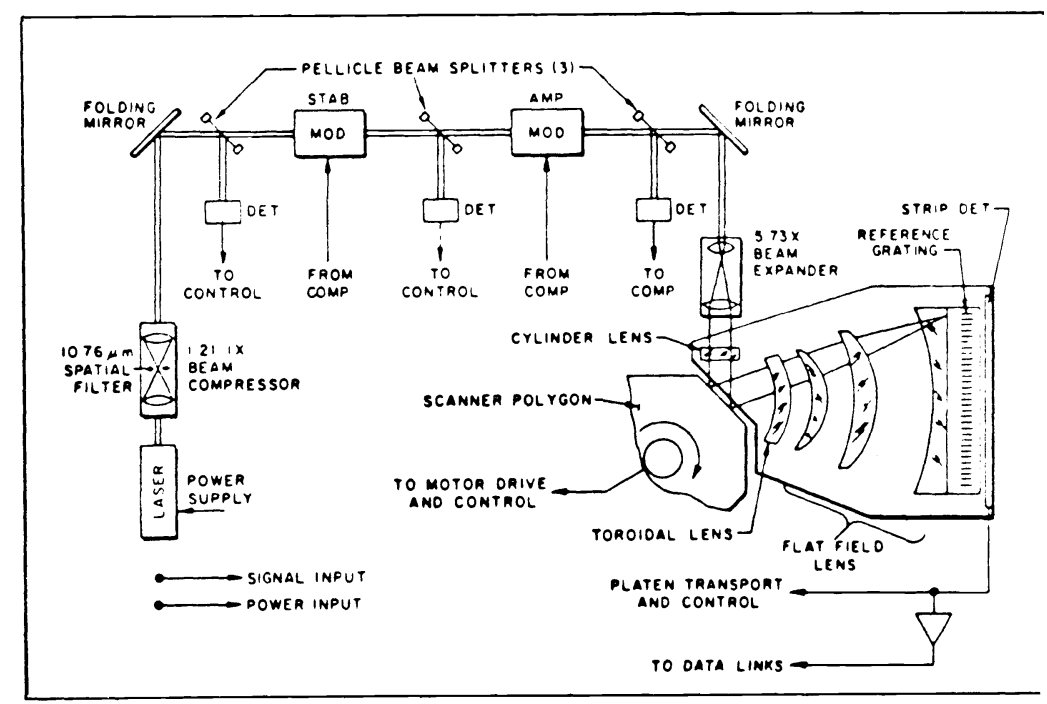

Fig. 3. Information Management System

Block Diagram, by I. C. Light, Optical Systems 


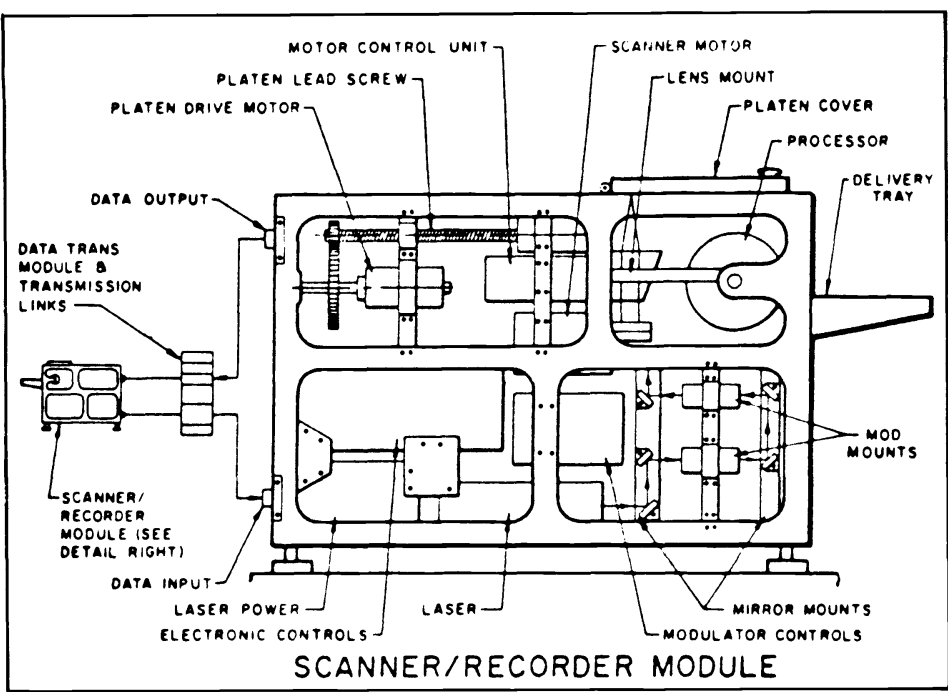

Fig. 4. Information Management System Block Diagram, by V. R. Stuffers, Packaging Department.
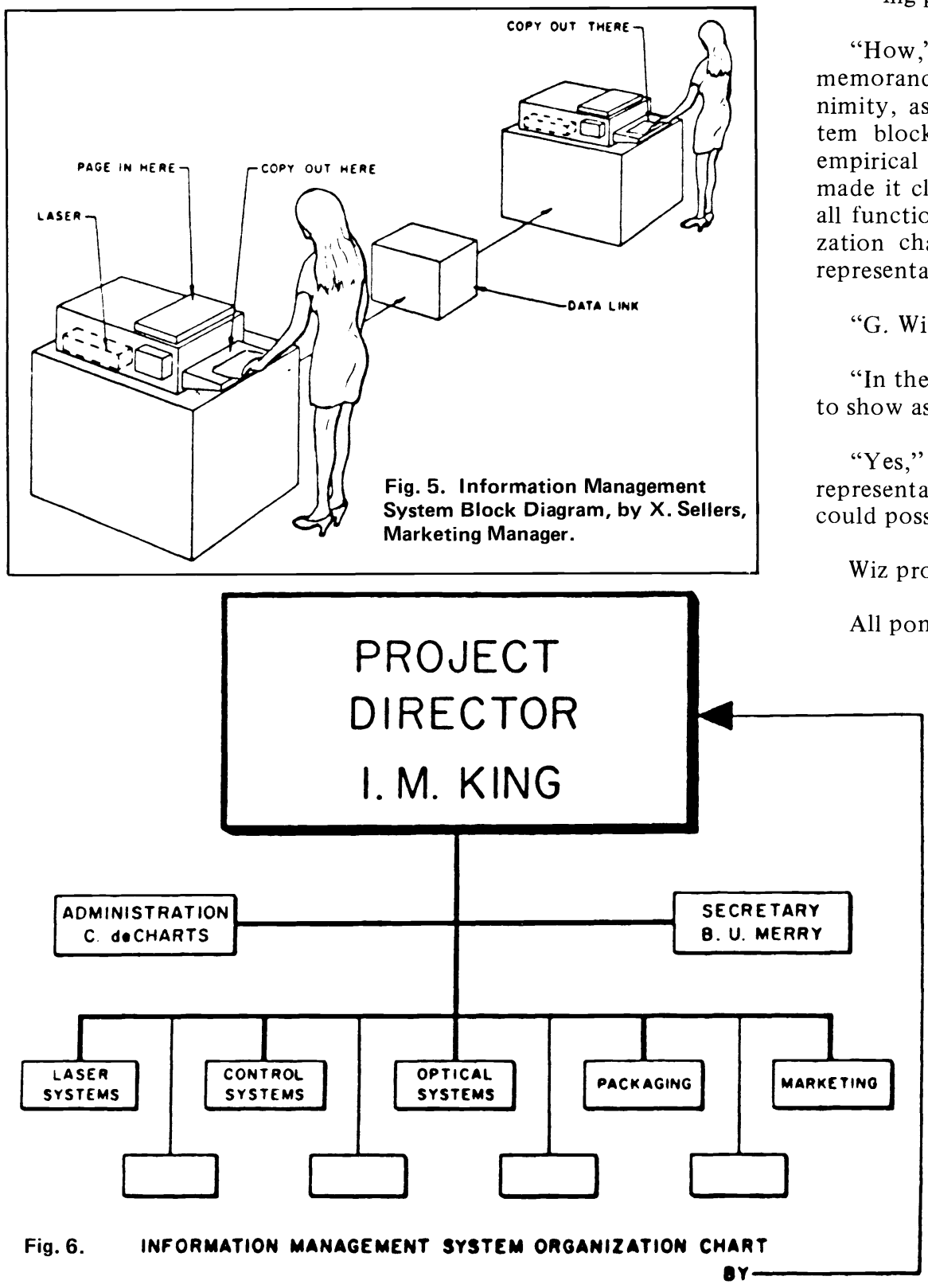

1. K. O. Heerent's laser was a masterpiece of alignability (as proven essential from extensive field reports) feeding light of unknown wavelength and power into minimodules of unspecified characteristics.

2. The V. R. Y. Stably-designed control systems were an outstanding achievement to overcome K. O.'s drifts and Engineering's mechanical shifts.

3. I. C. Light did construct an optical path with minimum components, consistent with its sparse accomplishment. The carefully calculated characteristics of the few chosen parts interfaced with no one, save the swapping of reflections with Stuffers.

4. Then Stuffers came through with his conglomerate of gray area black boxes firmly anchored in castings, ready for nameplates and serial numbers; while to C. deCharts, all that was needed was an orderly statement to the Customer as to its tolerable environs.

5. Finally, to X. Sellers came the genius flash of maximizing promotion from a base of minimum substance.

"How," asked King, "did this happen?" He read from his memorandum in which he called for a demonstration of unanimity, asking each group manager to present an entire system block diagram. What came out, he lamented, was an empirical representation of each group wearing blinders. $\mathrm{He}$ made it clear that this was to be a well-ordered composite of all functions. In fact, he recalled, he even distributed organization charts with the memo, to inspire a cross-the-board representation.

"G. Wiz-C. deCharts-where are they," hailed I. M. King.

"In the projector," whispered Wiz, "is the one you wanted to show as most important." [Fig. 6].

"Yes," said King, "-that one with the cross-the-board representation. Project it, for all to ponder over how this could possibly have happened!"

Wiz projected.

All pondered.

\section{Acknowledgment}

While this story is pure fiction, I wish to express my appreciation to all the organizations and their personnel who formed prototypes for the characters and "mature experience" represented here. Any resemblance to the real world is gratefully acknowledged as borne of this timeless resource of subject matter. 


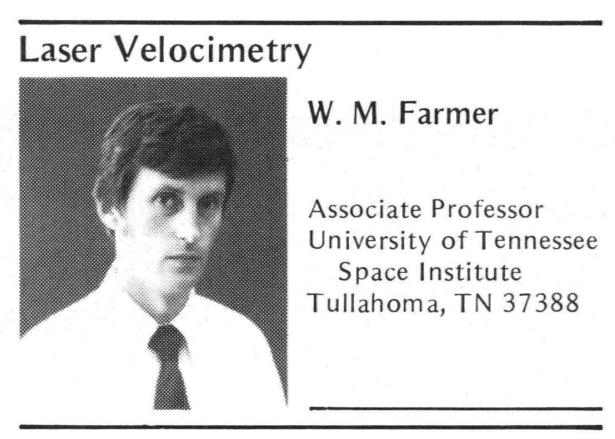

In beginning this column on Laser Velocimetry $I$ think it only appropriate to express my appreciation and that of the entire research community using laser velocimeters to John Caulfield for giving us this forum in SPIE Reports. In issues to come it will be my pleasure to describe new developments going on in the field, innovative applications, laser velocimetry in facilities in this country and abroad, to produce an occasional tutorial article, to express my own opinions about the status of the field, and to provide a forum for the exchange of information. To this end let me encourage those doing research involving laser velocimetry to keep me informed of their work.

\section{Data Biases}

It seems appropriate to begin a continuing discussion of laser velocimetry by briefly reviewing some of the areas that continue to significantly receive attention in research and development involving the instrument. One problem that continues to receive considerable attention is that of instrumental biases. These biases are usually understood to be systematic errors which must be compensated for either during experiment or during data reduction and analysis. A good review of these biases may be found in a PhD dissertation by Giel. ${ }^{1}$ Of particular interest in this area is the so-called problem of statistical bias. McLaughlin and Tiederman reported results in 1973 which suggested that laser belocimeters measured the speeds of faster particles in flows more often than slow particles. ${ }^{2}$ Hence, when statistical parameters such as mean velocity or turbulence intensity were computed, errors would arise because the data were not obtained in a truly random fashion. McLaughlin and Tiederman showed that this bias could be removed by computing, for example, the harmonic mean velocity rather than the arithmetic mean velocity. However, subsequent research did not find statistical bias to be a consistent effect. Giel found in his studies with a free jet that correcting for these effects often created additional error when the laser velocimeter results were compared with hot wire anemometer measurements. His conclusion was that there were numerous factors involved in the measurement process which tended to randomize the data and mask or eliminate the effect discovered by McLaughlin and Tiederman. As a result, data from each experiment should be carefully evaluated to decide if corrections for statistical bias are called for. Alternatively other workers proposed algorithms which could be used to randomize the data once it is acquired..$^{3,4}$

Discussion at the Third International Workshop on Laser Velocimetry at Purdue University showed that this question is far from resolved and will probably be the focus of much disccussion for some time to come.
Data recently published by Durao and Whitelaw suggest a data bias opposite that of statistical bias. ${ }^{5}$ These data show a decrease in velocimeter signal magnitude as particle velocity increases. The explanation put forth by these authors suggests that combinations of particle size relative to velocimeter fringe period and photodetector response time can be such that signal amplitude is reduced to zero. While their data do indeed show a dependence of velocity on signal magnitude and their explanation for the effect is reasonable, there exist other possible explanations for their results. No doubt considerable effort will be expended investigating these other possibilities and the potential effect this result has in understanding instrumental bias.

\section{"Two-Spot" Velocimetry}

Recent development of the "time-of-flight" or "two-spot" laser velocimeter as a useful research tool by a number of workers and at least two commercial companies has further increased the potential capabilities of laser velocimetry. These instruments obtain velocity measuremements by measuring the time-of-flight of particles between two focused spots. Because these spots are generally much smaller in diameter than the probe volume cross section of the more common fringe type velocimeters, spatial resolution is increased and laser power requirements are much reduced. Also, because the spots are generally widely spaced compared to their size, signal frequencies are generally much lower than those encountered with fringe type systems with subsequent increase in signal-to-noise ratio. Correlograms of the time intervals between signal pulses are usually obtained with this instrument in order to obtain mean velocity since numerous particles may pass through one focused spot and not the other. By using phototubes to detect each spot the direction of the flow can be determined using the correlator. However, with all its seeming advantages over fringe type velocimeters, two-spot systems apparently have limitations which seem to verify the adage, "Difficulty is conserved." Because the $\mathrm{F}$ numbers of the beams are relatively small, particular care must be given to aberrations which can enlarge the size of the focused spots requiring the use of increased laser power and a decrease in spatial resolution. No known method yet exists to quantify turbulence intensity with these instruments for a given spot orientation. Commercial two-spot LV systems are constructed such that the spots can be rotated by computer control in order to determine the primary direction of the flow and ultimately produce a two-dimensional velocity vector. Needless to say such an approach is expensive. At present, there is some debate among workers in the field over which approach is "better." No doubt applications exist where two-spot LV systems are superior to fringe velocimeters and vice versa. It seems to this writer that those instruments are mutually complementary and that ultimately hybrid varients will be developed to take advantage of the best characteristics of both approaches.

\section{True Gas Velocity}

A particularly exciting area in laser velocimetry, just in its infancy, is the true measurement of gas velocity. Current laser velocimeter systems infer gas velocity from measurement of light scattered from aerosols present in the gas. Obvious measurement errors result if the aerosol particles do not accurately follow the flow. It has recently been proposed, and preliminary experiments performed, to demonstrate the feasibility of directly measuring the velocity of individual sodium atoms using a two-spot velocimeter with a photon correlator to analyze the signal. ${ }^{6}$ In our laboratory at UTSI we have also performed preliminary experiments and analysis which suggest the feasibility of measuring true gas velocity using an entirely different approach. Much effort remains before such techniques will find their use as measurement tools. I am convinced, however, that such measurements are feasible.

\section{Three-Component Measurement}

Considerable effort has been expended in attempts to construct laser velocimeter systems which can simultaneously measure three componen ts of velocity. To construct a system which will measure three components at a point is relatively straightforward providing there are no window restrictions and the measurement point does not have to be scanned. Unfortunately, for most velocimeter systems these requirements are a basic necessity. As a result, numerous variations of basic optical geometries have been tried, none of which has been found to be fully satisfactory and generally accepted. It can be expected that developments in this area will continue to be forthcoming as the need for three-dimensional measurements increases.

\section{Signal Processing}

The past five years have witnessed a small revolution in laser velocimetry signal processing. With the advent of microprocessor technology, burst type signal processors have been developed which can be programmed for optimum response to a given optical geometry, have frequency responses well above $100 \mathrm{MHz}$, and have data acquisition rate capabilities approaching $1 \mathrm{MHz}$. Even with this kind of capability, burst processors are being pushed by frequency trackers in certain experimental applications, and photon correlation techniques have become extremely competitive. With these tools researchers are now faced with staggering problems of data management and interpretation. Even a two-component fringe type velocimeter system with scanning capability and burst type signal processors can fill a large minicomputer memory in times significantly less than 1 second. In addition to the fact that signal processors will continue to become more sophisticated, it is apparent that research must continue in order to understand how to be more data selective and to acquire data in the most efficient manner.

\section{Particle Size Analysis}

A particularly fruitful area for research involving laser velocimetry has been particle size analysis. At least three approaches are currently being used to size particles with a laser velocimeter. The first approach involves correlating particle size with drag velocity by measuring the aerosol in a known gas flow such as a shock wave or in a sinusoidal velocity flow such as generated by an acoustic speaker driven at constant frequency. A second method involves correlating particle size with signal magnitude using Mie scattering theory. Still a third approach involves measuring signal visibility or contrast which is correlated 
with the size of the particle relative to the velocimeter fringe period. Each of these techniques has been used in a variety of applications and significant effort continues in their development.

In touching briefly on some of the major research areas involving laser velocimetry I believe we have found a child of the laser still in adolescence but mature for its age.

\section{References}

1. Thomas Vincent Giel Jr., "Studies of Statistical Bias in Turbulent Flow Parameters Measured with a Laser Velocimeter," PhD Dissertation, Dept. of Aerospace and Mechanical Engineer, Notre Dame, Indiana, August 1978 .

2. D. K. McLaughlin and W. G. Tiederman,
"Biasing Correction for Individual Realization of Laser Anemometer Measurements in Turbulent Flow," Phys. Fluids, 16, 2082 (1973)

3. D. F. G. Durão, "The Application of Laser Anemometry to Free Jets and Flames with and without Recirculation," PhD Dissertation, University of London, 1976.

4. P. Dimotakis, "Single Scattering Particle Laser Doppler Measurements of Turbulence,' AGARD CP1 93, Paper 10.

5. D. F. G. Durão and J. H. Whitelaw, "Relationship between Velocity and Signal Quality in Laser Doppler Anemometry," J. Phys. E. 12, (1979).

6. C. Y She, W. M. Fairbanks, and Kenneth W. Billman, "Measuring the Velocity of Individual Atoms in Real Time," Optics Letters 2, 30 (1978).

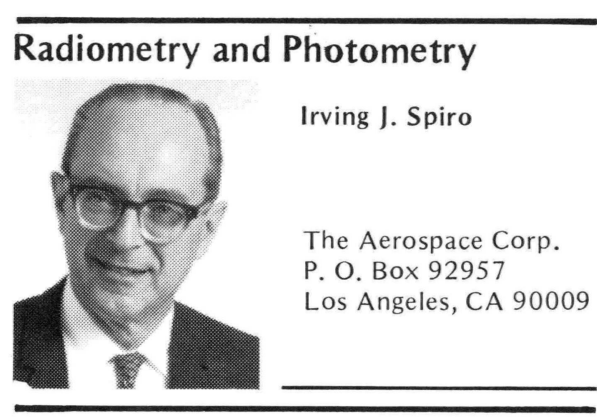

Review of the Book

Detection of Optical and Infrared Radiation

by R. H. Kingston

Elsewhere in this issue, the R. H. Kingston book entitled Detection of Optical and Infrared Radiation is reviewed by my colleague, Dr. William Chan of The Aerospace Corporation (who is also an instructor in Infrared Detector Technology at one of the local colleges).

I asked Dr. Chan to review the book because I had difficulty following some of the derivations, particularly those with some unfortunate omissions involving solid-state electronics. In fact, I found the book difficult to follow because many assumptions and definitions were not clearly stated. My overall impression is that the book was intended for use in class with an instructor, and not as a self-teacher.

I liked his derivations of NEP and $\mathrm{D} *$ for the various conditions, e.g., Signal-Noise Limited, Background-Noise Limited, Thermal Noise, but after awhile one becomes saturated with mathematical derivations of detection with no examples to illustrate the practicality of derivations.

Perhaps my greatest objection to Kingston's book is the lack of mention of any detectors or specific detector performance. One would expect that a text on detection of infrared radiation would at least mention the various detectors, their spectral and thermal limitations, and examples of where lead sulfide would be chosen over mercury cadmium telluride.

Another serious limitation in a book on "detection" is in the complete lack of any discussion of multiple detector arrays such as chargecoupled devices (CCDs) and mosaic detectors.

The good features of the book are the summary at the beginning of each chapter and the questions at the end of each chapter.

\section{The Business Side of Optics}

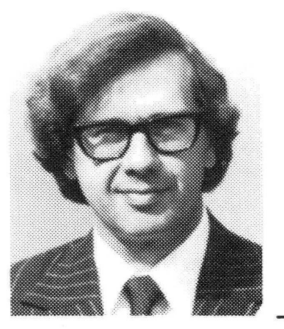

Curt Deckert

Technical and

Management Consulting 18061 Darmel Place

Santa Ana, CA 92705

In this issue we will consider the process of Program Planning in Industry. This article will be helpful to most optical businesses, but will be especially helpful to those who pursue business with the DoD, other government agencies, or large corporations. The resultant efficiency from going through the planning process presented can be greater efficiency so that products and services are available at a more attractive price. This paper was given at the SPIE Management of Optics Programs seminar, May 24, 1979, in Huntsville, Alabama. The complete version appears in SPIE Proceedings Volume 188.

\section{Program Planning in Industry}

\section{Robert H. Carpenter}

Rockwell International

Anaheim, California 92803

\section{Abstract}

Have you ever been surprised at the results of a competitive procurement? The winner or winners, the losers, the mix of the teams, the contract value, etc.? This paper bears directly on the above factors and also hopes to provide insight into why industry sometimes does and sometimes does not choose to invest its R\&D and marketing resources in optics program opportunities. Indications of how both government and industry benefit through open and equitable communications in their respective planning activities will be concluded.

\section{Introduction}

Program planning by industry has existed in a variety of forms for many years. The evidence of the effectiveness of this planning, i.e., successful companies, is too powerful to ignore. However,

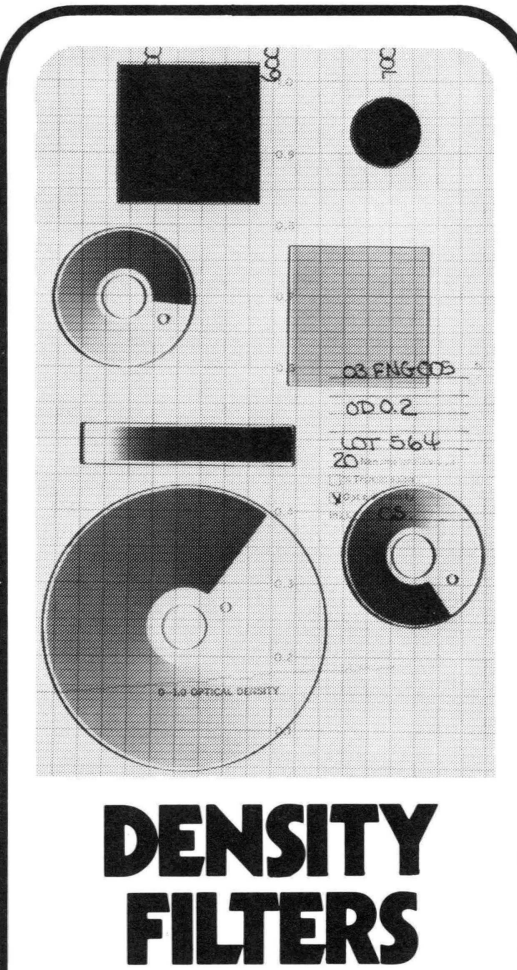

The Melles Griot Optics Guide lists 82 individual metallic neutral density filters. In precise detail. And it tells you how to use them effectively.

Densities range from 0.04 to 4 . Square and circular; glass or silica substrates. Step filters. Linear wedges. Circular wedges. Neutral density filter sets.

All are available from stock.

For complete details and price consult your Optics Guide. If you don't have a copy of our useful 192 page reference catalog, write or phone your nearest office.

Nieuwe Kade 10 6800AN Arnhem, Holland Phone: 085-229011, Telex: 45940

55 Sea Cliff Avenue Glen Cove, NY 11542

(516) 676-1660, Telex: 96-7797

1770 Kettering Street Irvine, CA 92714, (714) 556-8200 TWX: 910-595-1536

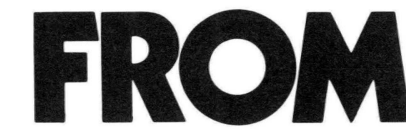
TELLES CRIOT

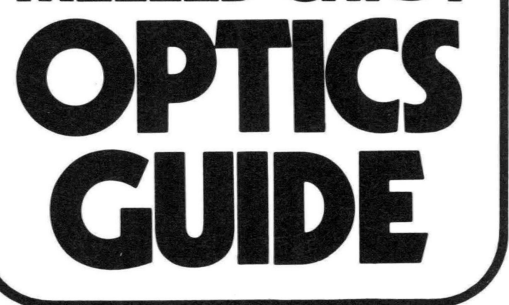


a list could also be developed of those who tested a particular business area and withdrew. Over the years, certain segments of industry have acquired the aura of being both superficial and inconsistent in their planning processes. Some individuals and their companies developed the undesired but well deserved image of being "shotgunners." The question to be considered is the extent to which effective program planning really makes a difference.

What changed the world around for industry planning was the budget crunch which has developed in recent years within DoD. The expression "Fixed Sum Game" used in industry is a way of life for DoD. This means prioritization, goal setting, contingency planning, defining and assessing risk, commitment of resources, "keeping it sold," etc. It also means limited discretionary resources at the "profit center" level.

\section{Program Planning Data}

The quality of program planning data, information, and intelligence must be at least adequate if there is to be effective planning in industry. The means used by industry to acquire these data vary greatly and are, in the au thor's opinion, much more of an art than a science.

Program planning information comes from: personal contact; briefings to industry; meetings and symposia; the media; Commerce Business Daily; long-range planners; Congressional records; budget details; consultants; etc. A typical aerospace organization maintains field offices staffed with qualified personnel. It also has senior management, marketing, engineering, and program management personnel who visit customers, potential customers, and points of influence in the pursuit of developing good program planning and decision criteria data. The cost to the companies, but ultimately to the government, of these capabilities and services is substantial. DoD planners should be conscious of their responsibilities for seeing that the information flow is adequate and consistent with the expenses of industry to acquire the data.

\section{Strategic Business Plan}

Within the industrial sector, every company has some manner of a Long Range or Strategic Business Plan for establishing goals and allocating resources. Smaller organizations may have informal resource allocation and prioritization activities understood only by the chief executive. May the Force be with him!

A Strategic Business Plan often emphasizes long-term entrepreneurial business planning. Therefore, the Strategic Business Plan process must concentrate on the analysis, planning and actions needed to develop successful products and programs for the future. This set of early planning activities is referred to as the "Preparation Phase." It includes future technology development, product definition and product development.

Proper planning and investment during the preparation phase can significantly reduce risk and improve returns during the "Performance Phase" (Figure 1). Furthermore, management's contribution can be most effective during the planning and preparation phase.

Strategic business planning has as its ultimate objective assisting the company profit center manager in establishing and meeting his commitment. The general manager commits yearly through the Strategic Business Plan and Annual

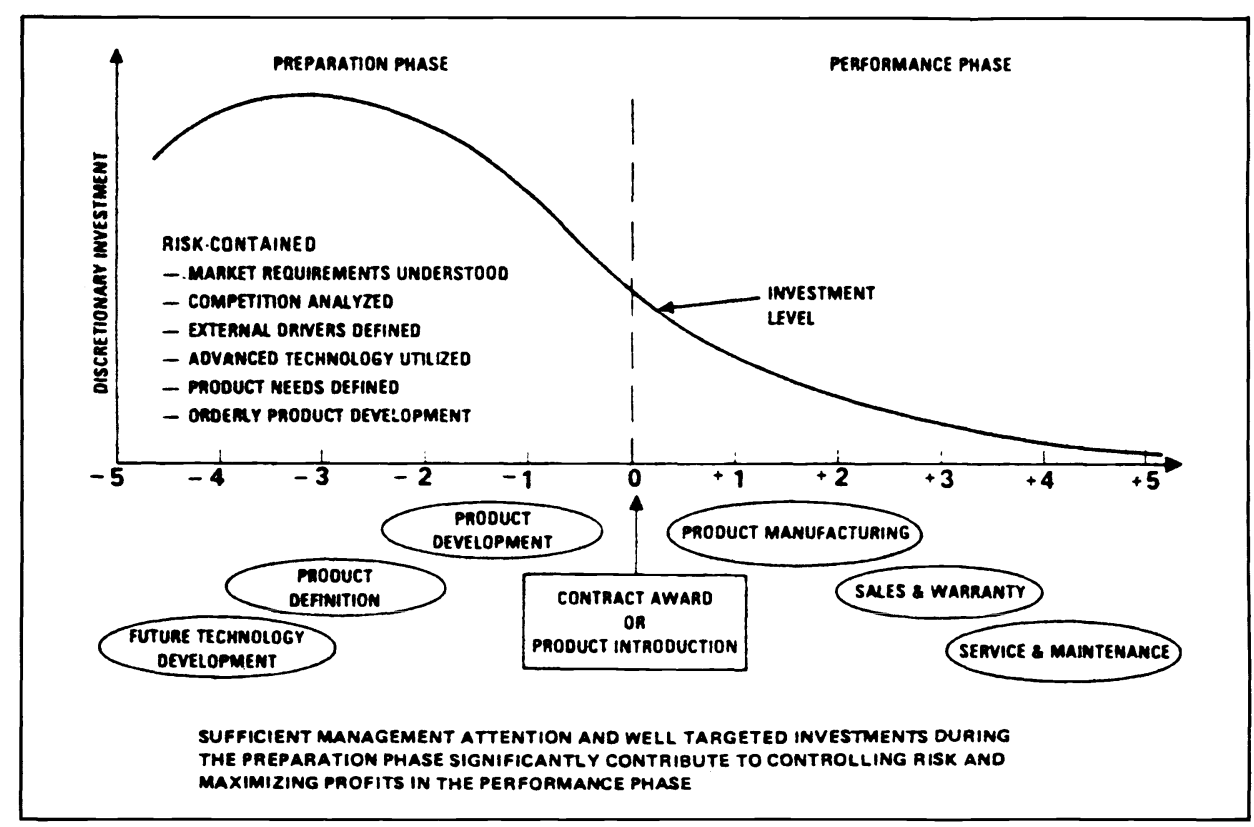

Figure 1. Optimum Preparation Phase.

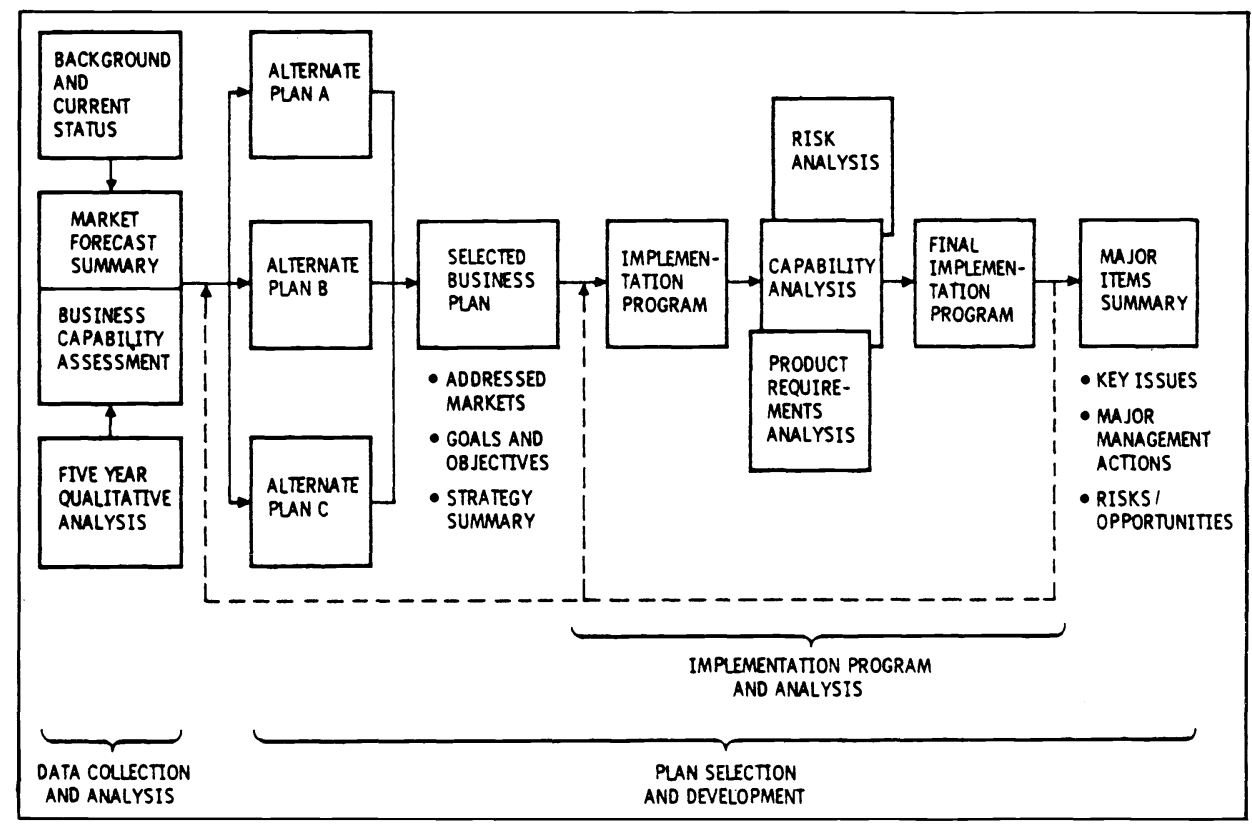

Figure 2. Flow of Business Segment Long-Term Planning Activities.

Operating Plan to define his plan, acquire upper management approval, and to share his commitment with his subordinates.

In order to effectively describe a Strategic Business Plan (a typical flow diagram is shown in Figure 2), it is necessary to define its elements. They include: Market Segment Identification; Anticipated Market Growth; Market Size and Targeted Market Share; Market Characteristics; Competitive Analysis; Contingency Planning; and Key Issues. The Strategic Business Plan is normally followed by the preparation of detailed Implementation Plans for specific business areas.

\section{Implementation Plan}

The preparation of an Implementation Plan is often accomplished with the aid of a form similar to the one shown in Figure 3. The form serves as the medium for consolidating and presenting data and planning information that has been developed. The objectives and goals for a particular business segment must be concisely articulated and shown to be consistent with the overall objectives and goals of the company. Inputs must be evaluated and integrated to formulate the strategies and specific actions that are necessary to attain, with high probability, the stated objectives and goals. Time-phased resource requirements and related contracts are shown.

The purpose of the Implementation Plan is to assure that the actions are defined and the budgets allocated to meet the stated business goals. An Optics Implementation Plan would be typical for a company seeking a specific market share of the DoD optics business. Within a typical industry situation there will be multiple Implementation Plans which are essentially subelements of 


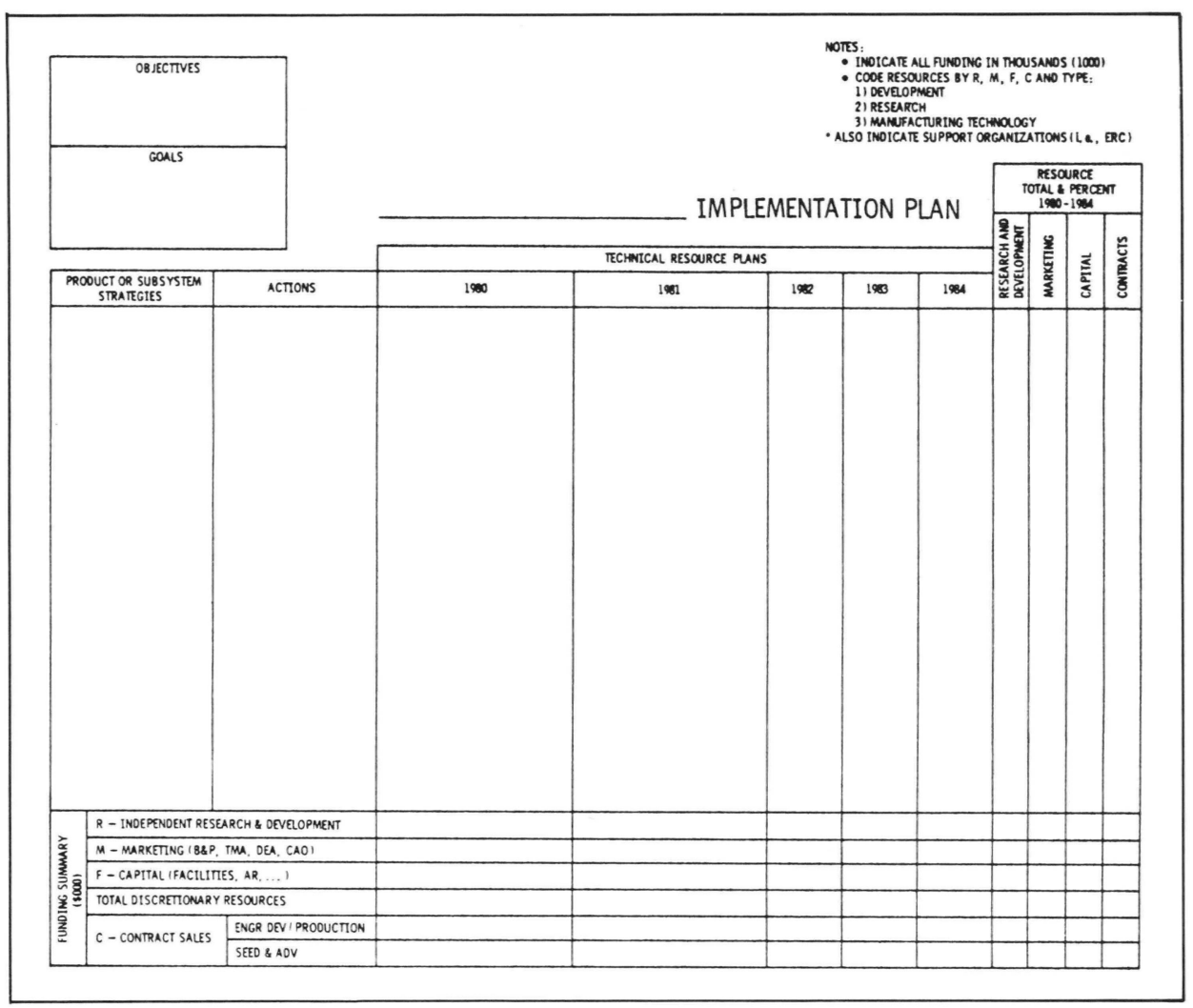

Figure 3. Implementation Plan Form. the Strategic Business Plan. Not surprisingly, those Implementation Plans and the resources identified in terms of independent research and development, marketing, facilities, etc., may exceed the total Strategic Business Plan funding available.

There is a continuing, on-going competitive situation within industry that is both normal and healthy. This competitive situation results in an opportunity for management to exercise its options by rigidly following the plans as defined or to consider them flexible. If they choose the latter course, there will be a vying for incremental additional funding.

It has often been said that the hardest sell, or toughest customer, is internal to the company, the implication being that the external environment is much more predictable. Realistically, what this means is that a variation from a business plan which requires greater than planned funding is going to require a thorough and convincing argument to obtain the required discretionary resources, since the resources normally will come from reprioritizing or taking away from another opportunity wherein events have not occurred as predicted.

An effective business development manager in defining his business area, resources required, anticipated results, etc., will develop an Implementation Plan which he works to, tracks to, and changes as events occur. The elements of his plan typically include: Description; Background-it treats in a summary fashion why your company is, or should be, in the business that you have chosen, would note the technology or technol-

\section{CTV FRAME GR
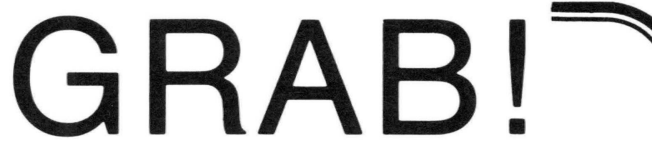 Grab it, store it, process it.}

The CVI 274 Video Frame Store allows you a choice:

- put video in, get either digital or video out

- put digital in, get digital or video out

Standard features:

- 256 level grayscale

- resolution to $256 \times 512$ pixels

- store a single field or full frame of video

And the 274 interfaces easily with most minicomputers.

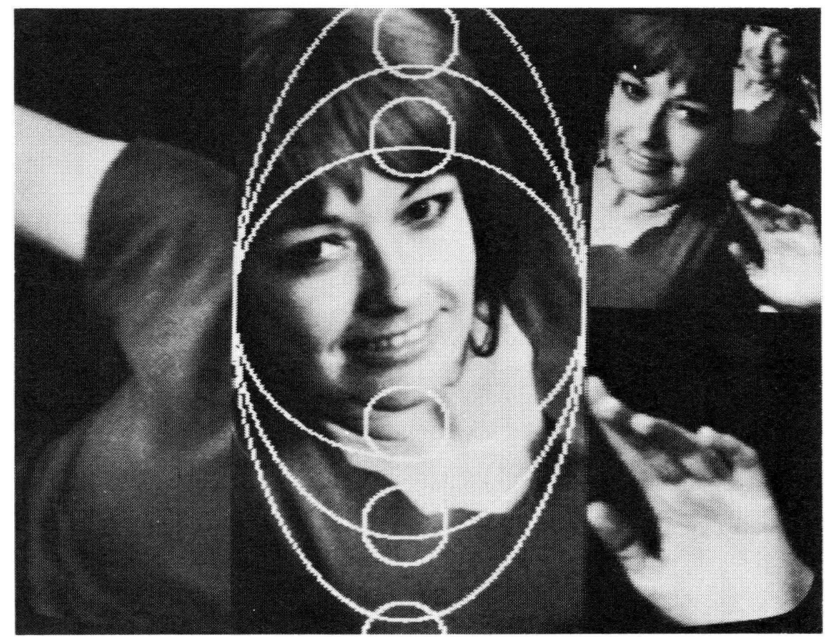

Specifications cheerfully sent on request.

\section{Colorado Video Incorporated}

Box $928 \bullet$ Boulder CO 80306 USA • 303/444-3972 • TWX 910-940-3248 (COLO VIDEO BDR) 
ogies involved, unique characteristics, needs, proprietary position, etc.; Market Definitionthis would include documentation, historical data, competitive position, sector of market selected, decision points, etc.; S trategies-a basic strategy which should be able to be easily articulated; Pricing-particularly in the segments of the market that involve production, a realization of acceptable potential production price levels is an important factor in making decisions and commitments of facilities; Discussion of Competition-this provides a profile of the competition's activities, strengths, and market share as shown in Figure 4; Advertising and Trade Show participation; Investment Analysis - this includes all classes of discretionary resources and timing, criteria or conditions which would be cause for withdrawal from the business area; Services Required; Personnel Requirements; and Market Outlook.

\section{Bid Decisions}

A vital part of dynamic business area management is the handling of specific opportunities. Historical data indicate that the likelihood of winning competitions you hadn't planned on is pretty slim. Therefore, various segments of in dustry have developed "Bid/No Bid" decision criteria which are used at the "Bid/No Bid" type of meeting which normally precedes the formal request for proposal or request for quotation by weeks to months, depending upon the opportunity. The purpose of the formalized criteria which causes the involved individuals to define their rationale in a written form is to develop coherent data to support the allocation of resources. There is a desire to base bid decisions upon logic and not emotion.

Typically, the business development team has preconditioned its company's management for the coming event. They have: forecasted the timing and the anticipated contract value; identified the competitors-with their perceived strengths and weaknesses; the probable evaluators have been named; a mock work statement has been developed; a proposal cost estimate has been made; the relationship of the opportunity to the Strategic Business Plan is reinforced; a probability of success-usually a percentage-is boldly offered; and then management is asked to commit the necessary resources.

An example of "Bid/No Bid" criteria,weighting, and evaluation is shown in Figure 5, a "Business Desirability Checklist" which is used prior to and at the bid decision activity. The utility of the "Business Desirability Checklist" in comparing to other probable competition through development of numerical ratings is apparent.

\section{Conclusions}

Why would the Program Manager be surprised at the extra commitments which an industrial firm might choose to include in its offer, such as the superior quality and experience of the people involved, a willingness to commit company resources in addition to the contract funds available, the special attention by top management, the relating of other company-sponsored activities to the general program objectives, etc.? These actions all reflect an intense desire of the management of a company to win the contract and participate in the particular activity. This means that its business development personnel have done an effective job of communicating the priority, the potential, and the significance of

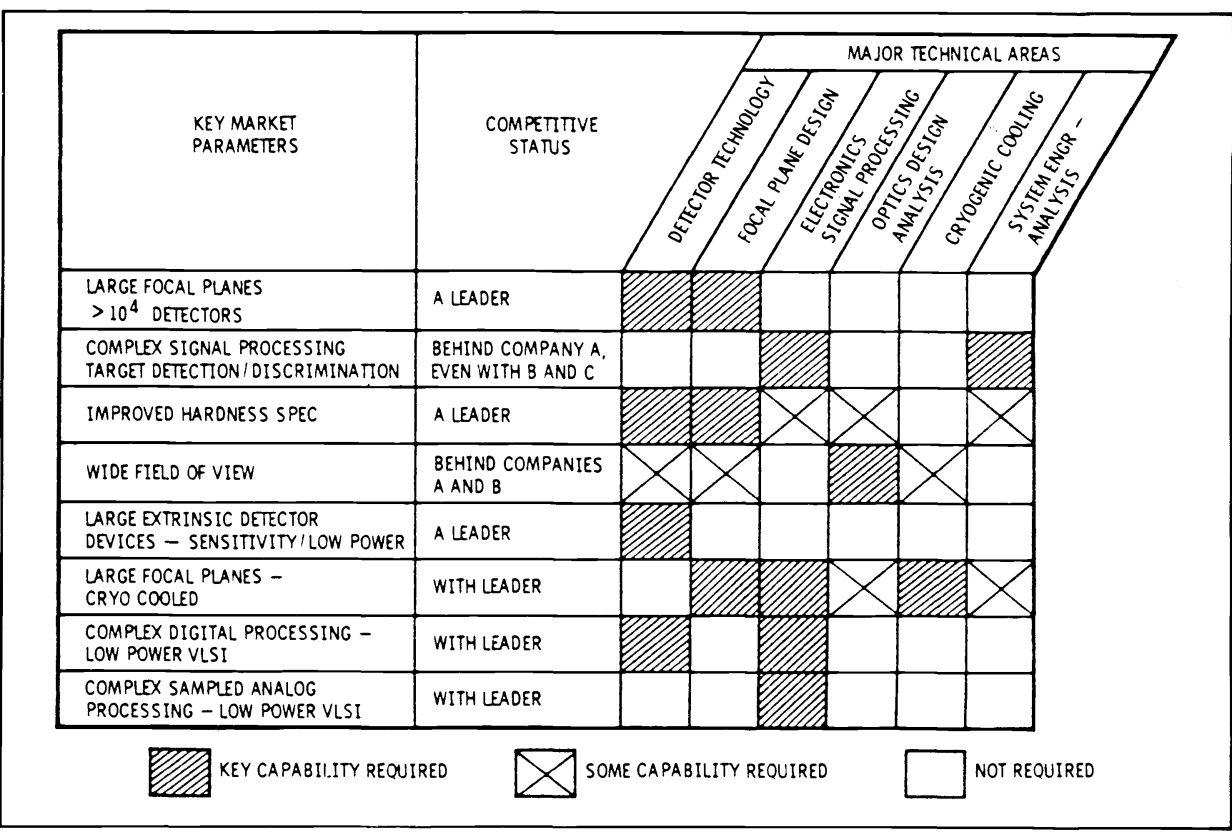

Figure 4. Optical Systems Capability Analysis.

\begin{tabular}{|c|c|c|c|c|c|c|c|}
\hline \multirow{2}{*}{ BID FACTOR } & \multicolumn{3}{|c|}{$\begin{array}{l}\text { WEICHTED DECISION CRITERIA } \\
\text { POSITIVE } \\
\text { NEUTRAL IECATIVE }\end{array}$} & \multicolumn{4}{|c|}{ ESTIMATED RATING } \\
\hline & $\begin{array}{llll} & 905110 & \\
10 & 9 & 7\end{array}$ & \begin{tabular}{|lclll} 
& NEUIKAL & \\
6 & 5 & 4 & 3 \\
\end{tabular} & \begin{tabular}{|l|l|} 
NEATIVE \\
2110 \\
\end{tabular} & $\begin{array}{c}\text { ROCKWELL } \\
\text { INTL }\end{array}$ & $A$ & B & $\mathrm{c}$ \\
\hline $\begin{array}{l}\text { 1. BACKGROND (Contract } \\
\text { OR Ci funded experi- } \\
\text { enc) }\end{array}$ & $\begin{array}{l}\text { Strong in-house } \\
\text { experience }\end{array}$ & $\begin{array}{l}\text { Averg. in-house } \\
\text { or inported }\end{array}$ & $\begin{array}{l}\text { Weak or new } \\
\text { area }\end{array}$ & & & & \\
\hline $\begin{array}{l}2 . \text { OERALL TEGANICAL } \\
\text { CAPABILITY }\end{array}$ & $\begin{array}{l}\text { Technically } \\
\text { superior }\end{array}$ & Capable & $\begin{array}{l}\text { Not qual i- } \\
\text { fiod }\end{array}$ & & & & \\
\hline $\begin{array}{l}\text { 3. PROPOSED TENM } \\
\text { (Human resources) }\end{array}$ & $\begin{array}{l}\text { Best and } \\
\text { availabie }\end{array}$ & $\begin{array}{l}\text { Best available } \\
\text { or imported }\end{array}$ & \begin{tabular}{|c|c|c|c|} 
Second \\
string
\end{tabular} & & & & \\
\hline $\begin{array}{l}\text { 4. FACILITIES } \\
\text { (Inhuman resources) }\end{array}$ & $\begin{array}{l}\text { Available and/ } \\
\text { or favorably } \\
\text { located }\end{array}$ & No impact & \begin{tabular}{|l|l} 
New facil- \\
ities ree- \\
quired
\end{tabular} & & & & \\
\hline $\begin{array}{l}\text { 5. SUBCONTRACTORS } \\
\text { (Team arrangenents) }\end{array}$ & Enhancing & No impact & Diluting & & & & \\
\hline 6. SARRETING & $\begin{array}{l}\text { Inside track. } \\
\text { Good work-up }\end{array}$ & $\begin{array}{l}\text { Generally up } \\
\text { to date }\end{array}$ & $\begin{array}{l}\text { Supervised } \\
\text { by the RFP }\end{array}$ & & & & \\
\hline$\therefore$ CUSTONER RAPPORT & $\begin{array}{l}\text { Cood working } \\
\text { relationships }\end{array}$ & $\begin{array}{l}\text { Known but not } \\
\text { cult tivated }\end{array}$ & Uniknown & & & & \\
\hline 8. COMPETITION & Sole source & $\begin{array}{l}\text { Open or } \\
\text { unktrown }\end{array}$ & \begin{tabular}{|l|} 
Wire for \\
competitor
\end{tabular} & & & & \\
\hline 9. RESPONSIBILITY & $\begin{array}{l}\text { Can meet/ex- } \\
\text { ceed every } \\
\text { requirenent }\end{array}$ & $\begin{array}{l}\text { Understand the } \\
\text { problem and } \\
\text { can respond }\end{array}$ & \begin{tabular}{|l|} 
Don't know \\
or have a \\
better idea
\end{tabular} & & & & \\
\hline 10. PRICE STRATEG & $\begin{array}{l}\text { Honest, credi- } \\
\text { ble and within } \\
\text { known } 1 \text { imits }\end{array}$ & $\begin{array}{l}\text { Reasonable and } \\
\text { competitive }\end{array}$ & \begin{tabular}{|l|} 
Must cut \\
comerss, \\
cost hhare, \\
etc.
\end{tabular} & & & & \\
\hline \multicolumn{8}{|c|}{ TOTAL SCORE (Sum of scores for each factor evaluated) } \\
\hline \multicolumn{4}{|c|}{ MAXINUM POINTS AVAILABLE ( $10 \times$ No. of factors evaluated) } & & & & \\
\hline \multicolumn{4}{|c|}{ DECISION $\quad$ Interest $\square$} & sue $\square$ & $\square$ & $\square$ & \\
\hline
\end{tabular}

Figure 5. Business Desirability Checklist.

the program. Therefore, in the author's opinion, the government is the beneficiary of a really strong effort. On the other hand, if the opportunity and its relationship to other DoD programs is a well-kept secret, the resultant offers may be fairly disappointing when the time comes to evaluate the proposals received. The cost of producing a superior proposal is significant, it ties up the energies of the company's most creative people, and it therefore behooves all those involved to play their "blue chips" prudently.

Without reasonable dialogue with the DoD planners and the military service Program Man- agers in implementing those plans, industry is less likely to do an effective job. On the other hand, with good and equitable planning information made available and communication lines kept open, industry can develop reasonable plans, identify their opportunities, their limitations, and define the factors involved which will allow them to relate a particular opportunity to their plans and receive management support. The payoff to DoD must certainly be greater efficiency on the part of their contractors, which should ultimately mean that the products and services of industry are available at a more attractive price.

\section{Semiconductor Microlithography V \\ March 17-18, $1980 \quad$ San Jose Hyatt House San Jose, California}




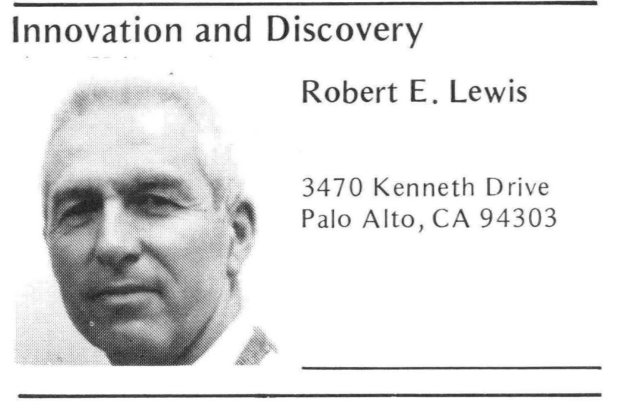

Technology Transfer "Piracy"

A color photomicrograph of a microprocessor semiconductor chip, much like its crude circuit board ancestor, reveals elements and geometry needed to duplicate it by semiconductor IC manufacturing steps. The original Mostek $16 \mathrm{k} \mathrm{dy}$ namic-RAM chip is reported to cost "two years and $\$ 3$ million," according to testimony before the U.S. House of Represen tatives subcommittee on courts, civil liberties and administration of justice. A "chip pirate" gets this for the cost of one device and the trouble of opening it.

Several years ago, at Teledyne Semiconductor, I became aware of "chip piracy" and began filing geometry copyrights for selected devices. To comply with the letter of the law, the copyright notice was even on every chip in letters .005 " high. There was a rumor that another group was also doing this, but we soon got strange copyright rejections on subsequent copyright applications. Further applications were dropped.

An effort to resolve this is bill H.R. 1007 to amend Section 1010 of the new Copyright Act of 1976 to include: "Such pictorial, graphic and sculptured works shall also include the photographic masks used to imprint patterns themselves, even though they are used in connection with the manufacture of, or incorporated in, a useful article." If this amendment or some such equivalent is not put in force, some contend that the reward then comes from production labor cost and marketing, not from innovation. The problem seems to hinge around non-patentability of valuable geometry developments.

In some areas, laws concerning industrial property apply to microphotomasks in certain circumstances, but nothing like a patent or copyright. Years ago, I picked up one of the easily recognizable dust-tight microphotomask carrier boxes which had been thrown in the trash bin with a few rejects left in it. Not long after I arrived home, I was telephoned asking why I was taking geometry home with me, etc. The masks had been discarded; I had taken the box to keep drills on the shelf in my garage. But the paranoia was evident.

On the other hand, if a factory in California terminates employment of some employees, the State of California assists them to find employment within the industry, and that is often with a competitor, who thereby acquires first-hand technique transfer.

With such situations in the USA, is it any puzzle that foreigh "pirates" arise and enter the market? What they "pirate" of USA geometry is just as legal there as it is here. We have similar problems with software. It is neither fish nor fowl, and as yet not clearly patentable nor copyrightable.

In other words, many reports are appearing which state that new developments in semiconductor geomerty and computer programs are not protectionable by normal means. This applies to much semiconductor microlithography output.

Patents and copyrights were once said to enable the originators to benefit thereby and continue to advance the state of the art. All too of ten today, the time a patent application is pending can be longer than the lifetime of the market. This is additional disappointment in our law. Congress is warming up to the need for better innovation protection and rewards to the originators. Maybe we need an invention of a new protection system or category to encourage innovation in mask geometry design.

\section{0) Revien}

DETECTION OF OPTICAL AND INFRARED RADIATION, R. A. Kingston. 140 pages; bibliography; index. ISBN 0-387-08617-X. SpringerVerlag New York, 1978, \$18.80.

Reviewed by William S. Chan, The Aerospace Corporation, P. O. Box 92957, Los Angeles, CA 90009.

This is a noble attempt in structuring the subject matter into a concise text for a one-semester or one-term course, as most texts in this area are usually bulky compilations of detector characteristics and peripheral subjects insufficiently coherent for a well-structured teaching text. Unfortunately, the subject of radiation detection seldom appears in the mainstream of physics or electrical engineering curricula, and a course in this area would be likely to be the first and the last most students will receive. As such, Kingston's book is more suitable for an advanced undergraduate rather than a graduate level course.

This text begins with a brief introduction to
Planck's Law, derives the basic expressions for detectivity and related quantities for various detection mechanisms, and concludes by citing applications in the fields of radar, radiometry, and spectroscopy

In the attempt to be concise, the book becomes a bland collection of mathematical derivations of physical quantities that provide very little incentive or enthusiasm to stimulate students into further inquiries of radiation detection in particular, and of electro-optics in general. Although the descriptions of the basic detection mechanisms of the various detector types are adequate from a teaching viewpoint for a rudimentary grasp of the detection means, there is a complete absence of discussion on examples of representative detectors, temperature dependence, spectral response, frequency behavior, and bias and amplifier requirements, all of which are necessary subjects to students aspiring to professional scientists and engineers who are serious about radiation detection. This conspicuous absence tends to leave the students with

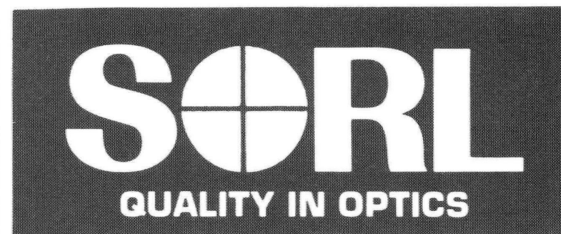

\section{OPTICAL TEST} STATIONS:

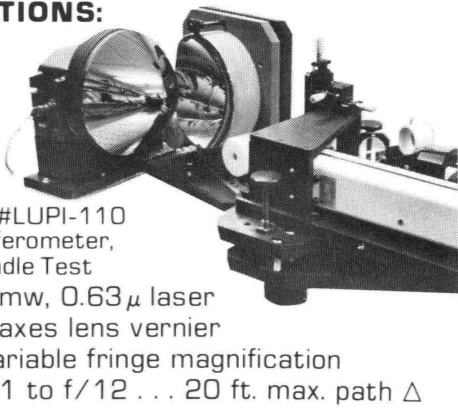

- f/1 to f/12 ...20 ft. max. path $\Delta$

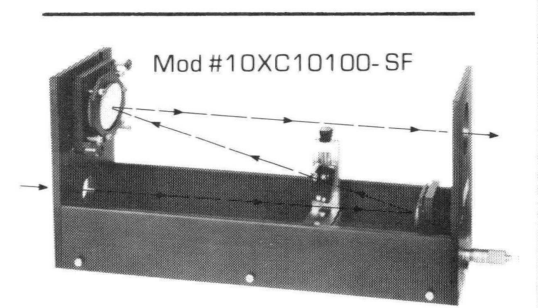

VISIBLE- $\mathrm{CO}_{2}$ REFLECTIVE COLLIMATORS

- $\lambda / 5 @ 0.63 \mu$. $99 \% R$

- $2 x-100 x$

- 25 - 200mm diameters

- Water-cooled - Spatial-filtered

\section{IR LENSES ... GERMANIUM / SILICON}

- IRWS48

3.2" fl, f/0.8-11, $11^{\circ}$ fov Mod

- IRWS 2, 8

3.0" fl, $f / 1.5-18,12^{\circ}$ fov

- IRWS285

1.7" fl, f/0.85-8, $21^{\circ}$ fov

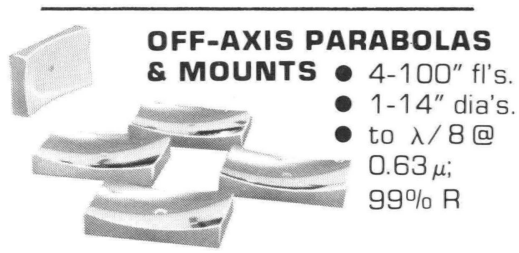

Mod \#0AP06-02-02

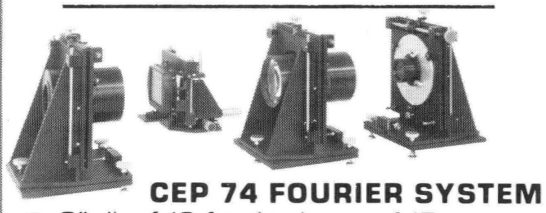

- 6" dia, $f / 3$ fourier lenses $f / 5$ collimator ... liquid gate, camera back ... 15 components

- FX15/5F System, 3" dia, f/5, $\lambda / 8$ @ $0.63 \mu / 1.5^{\prime \prime}$ dia. spatial Filter,

3 lenses and Manual

Call or write for catalog SPACE OPTICS RESEARCH LABS DIV. OF OPTRONICS INTERNATIONAL, INC. 7 STUART ROAD CHELMSFORD, MA 01824 (617) $256-4511$ TLX $94-7443$ 
the impression that radiation detection is as simple as the bare derivations imply and that detection requires no optimization but devoids sophistication and extensive applications othe than those limited examples cited in the text.

The richness and interesting aspects of radiation detection can hardly be attributed only to the areas of radar, radiometry and spectroscopy It seems that the lack of consideration of applications such as imaging, electro-optics and reconnaisance, in which detection plays a dominant role and demands the most sophisticated detection techniques, is a woeful shortcoming of the book. The appearance of a more compre hensive book entitled Optical and Infrared De tectors, edited by R. J. Keyes and published by the same publisher (Springer-Verlag) certainly can supplement much of the shortcomings of Dr. Kingston's text and can even serve better as a graduate text; however, a strong supplementary book to a weak text is not a wise choice by a course instructor and indeed not an economica text for the average student.

Dr. Kingston's style is readable and can be followed easily by students under self-study conditions. For the more diligent students, especially those who had prior exposure to radiation theory and infrared subjects, the whole text can be read at one sitting. However, there are some minor irritations, especially to uninitiated students, in lengthy derivations whose results are not emphasized and their significance insuf ficiently discussed, in typographical errors in equations, and in poorly defined terms used in the derivations. To this course instructor, the attractive features of the book are its concise ness, the compilation of problems at the end of each chapter, and the inclusion of chapters on detection statistics and atmospheric turbulence subjects which are usually not discussed in similar texts.

Having taught a similar course on infrared detection and having searched extensively for text suitable for that course, I found Dr. Kingston's book adequate on generality in radiation detection but very short in specifics as a text for an advanced undergraduate or a graduate level. I felt that the average student, after working through the text, will still have little appreciation on the applicability of the detector types and sophistication of radiation detection.

RADIOMETRIC CALIBRATION: THEORY \& METHODS, Clair L. Wyatt. 200 pages, index, bibliography, ISBN 0-12-766150-6. Academic Press, Inc., 111 Fifth Avenue, New York, NY $10003,1978, \$ 21.00$

Reviewed by Irving J. Spiro, The Aerospace Corporation, P. O. Box 92957, Los Angeles, CA 90009

This is a book which everyone concerned or connected with radiometry should have in their libraries. It is a model of how a technical book should be written. The book is well organized well presented, succinct and well written, and eminently suited as a reference book, selfteacher, and "how-to" book on radiometric instruments and their calibration.

All known factors affecting radiometric measurements are considered. Separate and detailed sections thoroughly discussing Spatial Temporal, Thermal, Spectral, and Polarization Effects are included. The first five chapters dea with radiation geometry, blackbody radiation and nomenclature. These provide a background for the balance of the book for the newcomer and a good review for all others.

All concepts are clearly and adequately stated, italicized for emphasis when required. Each equation has the proper units appended in square brackets. I especially like his use of alternate nomenclature, also in square brackets. For example, Wyatt calculates the solar constant and presents the results as, "the areance [irradiance] is $E=1 / S^{2}=k_{s} \pi r^{2} / S^{2}=1340[W] . "$

The book places emphasis on "Engineering Calibration" rather than the laboratory standard type. The various sources of anomolous results are pointed out together with the means of avoiding them. Thus, the difficulties associated with the use of a distant small area source are ex plained, and the use of a collimator to overcome the deficiency is explained (and illustrated)

The book concludes with examples of the engineering calibration of a cryogenic long wavelength infrared (LWIR) radiometer, and an interferometer spectrometer. The means of calculating the calibration accuracy based on the assumptions made (regarding linearity and curve fitting), are also presented. Complete references are provided at the end of each chapter.

In summary, I feel this book will soon become the standard of the industry for Radiometric Calibration. I recommend it to all of you.

HOLOGRAPHIC INTERFEROMETRY, Charles M. Vest xii + 465 pages. ISBN 0-471-90683-2. John Wiley \& Sons, 1978.

Reviewed by Gerald B. Brandt, Westinghouse R\&D Center, 1310 Beulah Road, Pittsburgh PA 15235

Vest has produced a book on holographic interferometry which very well may be a classic work about this most important of applications of holography. Part of the success of this book lies in Vest's careful scholarship, and thorough research into the field, and part of the success stems from the timing of the book which describes a field which has matured to the point where serious engineering analyses can be made using holographic interferometry. This is a must book for the practitioners of holography who want quantitative results from holographic interferograms and are willing to spend some effort in their interpretation. Vest is not trying primarily to tell the reader how to design and construct experiments but rather is explaining what the data mean once he has them or how to optimize sensitivity to the type of data which he wants to acquire. The author, in his introduction, prom ises that the proofs and arguments will stress physical rather than mathematical principles. Generally this is true, however it does not follow that the book is devoid of math. On the contrary particularly in the sections dealing with fringe localization and stress analysis, the analyses, though clear, lead to some formidable equations. Much of this analysis can be passed over by the reader who is not interested in the proofs and wishes to reach the end applications quickly. For further details on any of the topics the reader is referred to the excellent set of references at the end of each chapter, an important feature since the optical journals contain additional details about the various techniques.

Although formally the book is divided into seven chapters, for this discussion the subject matter divides into four general areas, namely: Introductory material, discussion of opaque holographic interferometry, transparent holographic interferometry and other techniques (speckle, contour generation, etc.).

The introductory sections are intended to bring the reader up to speed about holography without the use of Fourier transform theory. This goal is achieved for someone who is knowledgeable about moded optics but the introduction is very concise and would be inadequate by itself for the novice readers.

The section concerning opaque interferometric techniques is the most extensive of the four since it embraces the topics of fringe interpretation and localization, as well as stress and bending analysis for both statically and dynamically deformed objects. In this area considerable space is given to analyzing fringe formation and location and the manner in which these terms relate to the in and out of plane motions measured by the hologram. In the stress analysis discussions we learn about the basic relations between geometrical deformation and stress and how interferograms may be interpreted to extract the desired information. In analyzing vibration, the various time effects are described in detail.

In the third major area of the book, Vest discusses the important application of holographic interferometry to transparent objects and the general area of visualizing phase variations in fluid media. As in the rest of the book, the coverage is thorough and complete. Vest introduces his discussion with a description of optical path variation and refraction in phase objects. He continues with a description of techniques for, and illustrations of, interferometry of phase objects. As in the case of opaque interferometry, the properties of fringe localization are discussed at length. A section on non-linearity and fringe sharpening is followed by discussion of interpretation and applications. This section of the book is amply annotated with 251 references; by itself it would form an excellent monograph on the holography of transparent media.

The final section of the book may be considered miscellaneous applications which do not fit neatly into the two other broad categories. Here are discussed briefly such applications as contouring, speckle photography and interferometry, TV techniques and holographic photoelasticity. In summary, the four general areas of the book cover every important area of holographic interferometry.

In general, Vest's writing style is good, but very concise and compact. The book reads well but there is a lot of information buried in every paragraph. There are a number of practical details in each area, based on the author's personal work in the field as well as his ability to pick the important areas from the literature. The references to the literature are excellent and well balanced among the various workers in the field. (Karl Stetson, rightly enough, is the most frequently quoted reference.)

The production of the book is up to John Wiley \& Sons' high standards and the text is relatively free from typos. Separate author and subject indexes are provided-a nice touch. Since so much material is packed in the book, more subheading in the text and more subject index entries would make the book more easily used. In the next edition the subject index could be easily twice as long as it is now. These are minor criticisms and in no way detract from the book as a whole.

Holographic Interferometry is an excellently, tightly written monograph which is a must on the shelves of anyone working with holography. 